\title{
PLANEJAMENTO URBANO E ÁREAS PREDISPOSTAS A RISCO GEOLÓGICO EM BELO HORIZONTE: LIMITAÇÕES DA LEI DE PARCELAMENTO, OCUPAÇÃO E USO DO SOLO
}

\author{
João Pedro Martins da Cruz \\ Universidade Federal de Minas Gerais - UFMG \\ Graduacão em Geografia, Instituto de Geociências, Belo Horizonte, MG, Brasil \\ Centro Federal de Educação Tecnológica de Minas Gerais - CEFET-MG, Belo Horizonte, MG, Brasil \\ joao.pedro.10m@gmail.com \\ Malena Silva Nunes \\ Centro Federal de Educação Tecnológica de Minas Gerais - CEFET-MG, Belo Horizonte, MG, Brasil \\ Universidade Federal de Minas Gerais - UFMG \\ Pós-Graduação em Geografia, Instituto de Geociências, Belo Horizonte, MG, Brasil \\ malena nunes@yahoo.com.br \\ Ricardo José Gontijo Azevedo \\ Centro Federal de Educação Tecnológica de Minas Gerais \\ Departamento de Geografia e História, Belo Horizonte, MG, Brasil \\ ricardogeop@yahoo.com.br
}

\section{RESUMO}

Ainda que as características geológicas e geomorfológicas de Belo Horizonte não sejam favoráveis à ocupação, ela ocorre intensamente, justificando estudos que associem processos geomorfológicos com a ocupação permitida. Aspectos ambientais, como geologia e relevo, definem a predisposição ao risco geológico. Este trabalho objetivou, assim, realizar um levantamento das áreas predispostas a risco geológico elevado no município e relacioná-las com o zoneamento determinado pela legislação municipal. Para tanto, foram considerados um mapeamento de predisposição a risco geológico fornecido pela Prefeitura Municipal de Belo Horizonte e a Lei Municipal no 7.166/1996, que trata do Parcelamento, Ocupação e Uso do Solo, com suas alterações até o ano de 2016. Foi feita, por meio do software ArcMap, uma sobreposição das bases cartográficas de áreas predispostas a risco geológico elevado e zoneamento municipal, ambas fornecidas pela prefeitura. Observou-se que diferentes tipos de riscos ocorrem, em sua maioria, em áreas coincidentes e que as zonas de maior destaque quanto à predisposição a risco elevado foram, respectivamente, as Zonas de Adensamento Restrito-2, Preservação Ambiental, Adensamento Preferencial, Proteção 1 e Grandes Equipamentos. Portanto, tornam-se fundamentais intervenções e investimentos públicos nestas áreas para garantir melhor planejamento e, consequentemente, menor vulnerabilidade à população que vive nestes locais.

Palavras-chave: Urbanização. Áreas de risco. Legislação urbana.

\section{URBAN PLANNING AND AREAS PREDICTED TO GEOLOGICAL RISK IN BELO HORIZONTE: LIMITATIONS OF THE LAW OF PARCELMENT, OCCUPATION AND USE OF THE SOIL}

\begin{abstract}
Although the geological and geomorphological characteristics of Belo Horizonte are not favorable to the occupation, it occurs intensely, justifying studies that associate geomorphological processes with the allowed occupation. Environmental aspects, such as geology and relief, define the predisposition to geological risk. This work aimed to carry out a survey of the areas predisposed to high geological risk in the municipality and to relate them to the zoning determined by municipal leaislation. For that, a geological risk predisposition mapping was provided by the Belo Horizonte Municipal Government and the Municipal Law No. 7,166 / 1996, which deals with Land Taxation, Land Use and Land Use, with its changes up to the year 2016. It was made, through the software ArcMap, an overlay of the cartographic bases of areas predisposed to high geological risk and municipal zoning, both provided by the city hall. It was observed that different types of risks occur mostly in coincident areas and that the areas with the highest risk of predisposition to high risk were, respectively, the Restricted Area-2, Environmental Preservation, Preferential Density, Protection 1 and Large Equipment. Therefore, public interventions and investments in these areas become fundamental to ensure better planning and, consequently, less vulnerability to the population living in these areas.
\end{abstract}

Keywords: Urbanization. Risk areas. Urban legislation.

$\begin{array}{llllll}\text { Caminhos de Geografia } & \text { Uberlândia-MG } & \text { v. 20, n. } 70 & \text { Junho/2019 } & \text { p. 462-477 } & \text { Página } 462\end{array}$




\section{INTRODUÇÃO}

A questão ambiental tem sido evocada com frequência nos últimos anos, tendo em vista a maior preocupação em relação à preservação dos recursos naturais do planeta. No Brasil, a industrialização se consolidou a partir dos anos 1950, fazendo com que a expansão da ocupação dos centros urbanos ocorresse, em geral, de forma não planejada. Nunes (2015) destaca que a

expansão dos centros urbanos, determinada pela demanda de áreas e pelas restrições políticas que direcionam o uso da terra, está fortemente associada à vulnerabilidade da população, pois em muitos casos esse avanço se dá em direção a ambientes frágeis, como florestas, encostas e mananciais (NUNES, 2015, p.15).

Nesse contexto, destaca-se que os solos sempre foram alvo para aquisição de bens lucrativos, seja por meio da exploração mineral, do uso agrícola ou mesmo para construções civis, sendo que seu uso é realizado, muitas vezes, de maneira pouco racional, podendo causar uma série de degradações ambientais. A retirada da cobertura vegetal, por exemplo, pode originar processos erosivos intensos que, além de alterar substancialmente as paisagens, trazem prejuízos ao ambiente. Por vezes, as próprias características naturais de uma região, como o clima, a geologia e o relevo, intensificam a ocorrência de processos degradantes, como a erosão, processo natural que pode variar ao longo do tempo e do espaço onde ocorre.

A ação antrópica pode acelerar os processos erosivos, provocando danos na superfície e no ambiente. Guerra (1995) aponta que as características das encostas estão diretamente relacionadas à erodibilidade dos solos na medida em que, de acordo com a declividade, o comprimento e a forma da encosta, a erosão poderá ser minimizada ou maximizada. Gama (2004) acrescenta que o volume e o tamanho do material arrastado pela água variarão em função da velocidade com que ela escorre. Além disso, a retirada da cobertura vegetal e a impermeabilização do solo acentuam a ocorrência não somente da erosão, como também de movimentos de massa, que, segundo Bigarella (2003, p.1026) são "os mais importantes processos geomórficos modeladores da superfície terrestre", sendo os deslizamentos de terra e os escorregamentos os exemplos mais comuns em áreas urbanas. As próprias características do solo podem determinar o grau de erosão na medida em que as propriedades pedológicas são responsáveis por determinar a entrada de água no solo (permeabilidade), por exemplo.

A ocorrência de processos erosivos e movimentos de massa em centros urbanos torna-se preocupante na medida em que estes geram consequências impactantes para a população, já que, em muitos casos, as áreas de ocorrência coincidem com áreas ocupadas, acarretando em perdas de vidas e bens materiais. Nesse contexto, são definidas como áreas de risco os locais habitados onde há a probabilidade de alguma perda em um determinado tempo em virtude da presença iminente de um perigo, sendo que Kobiyama et al. definem perigo como "um fenômeno natural que ocorre em épocas e regiões conhecidas que pode causar sérios danos nas áreas sob impacto" (KOBIYAMA et al., 2006:17). Percebe-se, portanto, que a determinação da probabilidade de perda encontra-se associada a políticas públicas e à própria ocupação da área em questão. Os autores supracitados destacam os desastres naturais mais comuns nos países latino americanos, conforme Tabela 1. 
Tabela 1 - Desastres Naturais Discriminados por Tipo de Evento em Países da América do Sul no período entre 1960 e 2009.

\begin{tabular}{|c|c|c|c|c|c|c|c|c|c|c|c|c|c|c|c|}
\hline & 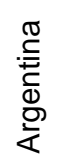 & 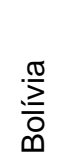 & $\begin{array}{l}\overline{\bar{g}} \\
\overline{\frac{\pi}{0}} \\
\bar{\infty}\end{array}$ & $\frac{0}{\frac{0}{J}}$ & $\begin{array}{l}\frac{\pi}{0} \\
\frac{0}{0} \\
\frac{\delta}{0} \\
0 \\
0\end{array}$ & $\begin{array}{l}\bar{\partial} \\
\frac{0}{0} \\
\bar{\partial} \\
\dot{\Psi}\end{array}$ & $\begin{array}{l}\frac{\widetilde{\sigma}}{\sigma} \\
\frac{\widetilde{\sigma}}{5} \\
\mathbb{0}\end{array}$ & 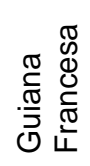 & $\begin{array}{l}\bar{\pi} \\
\frac{\pi}{\pi} \\
\frac{\pi}{\sigma} \\
\frac{0}{2}\end{array}$ & $\frac{0}{2}$ & 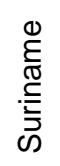 & 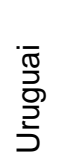 & $\begin{array}{l}\frac{\pi}{0} \\
\frac{N}{N} \\
0 \\
\frac{0}{0} \\
>\end{array}$ & $\begin{array}{l}\bar{\pi} \\
\stackrel{0}{\circ}\end{array}$ & $\circ^{\circ}$ \\
\hline Seca & 2 & 9 & 15 & 2 & 1 & 3 & 2 & 0 & 6 & 8 & 0 & 1 & 1 & 50 & 5,8 \\
\hline $\begin{array}{l}\text { Extremos de } \\
\text { temperatura }\end{array}$ & 7 & 3 & 7 & 5 & 0 & 0 & 0 & 0 & 2 & 6 & 0 & 3 & 0 & 33 & 3,8 \\
\hline Inundação & 45 & 32 & 101 & 26 & 60 & 22 & 6 & 1 & 15 & 39 & 3 & 12 & 24 & 386 & 44,7 \\
\hline $\begin{array}{l}\text { Movimento de } \\
\text { massa seca }\end{array}$ & 0 & 0 & 0 & 0 & 3 & 1 & 0 & 0 & 0 & 2 & 0 & 0 & 0 & 0 & 0,7 \\
\hline $\begin{array}{l}\text { Movimento de } \\
\text { massa úmida }\end{array}$ & 3 & 5 & 21 & 4 & 33 & 10 & 1 & 0 & 0 & 28 & 0 & 0 & 4 & 109 & 12,6 \\
\hline Incêndio & 5 & 3 & 3 & 6 & 2 & 2 & 0 & 0 & 1 & 1 & 0 & 0 & 0 & 23 & 2,7 \\
\hline Tempestade & 17 & 2 & 15 & 13 & 7 & 0 & 0 & 0 & 4 & 3 & 0 & 6 & 3 & 70 & 8,1 \\
\hline Terremoto & 3 & 3 & 2 & 14 & 21 & 11 & 0 & 0 & 0 & 31 & 0 & 0 & 7 & 92 & 10,7 \\
\hline Vulcanismo & 2 & 0 & 0 & 5 & 10 & 10 & 0 & 0 & 0 & 2 & 0 & 0 & 0 & 29 & 3,4 \\
\hline Epidemia & 2 & 11 & 15 & 1 & 2 & 11 & 0 & 0 & 6 & 11 & 0 & 0 & 6 & 65 & 7,5 \\
\hline Total & 86 & 68 & 179 & 79 & 139 & 70 & 1 & 1 & 34 & 131 & 3 & 22 & 45 & 863 & 100,0 \\
\hline
\end{tabular}

Nota-se que o Brasil se destaca com maior número de desastres naturais no período analisado, entre 1960 e 2009, sendo o maior deles a inundação, desastre natural que se intensifica com a ação humana e a falta de planejamento adequado nos centros urbanos. Assim, o interesse no estudo das áreas de risco surge na busca por evitar desastres naturais e minimizar suas consequências, já que muitos deles podem ser atenuados com a realização de um planejamento urbano que leve em consideração as características naturais do local em que será aplicado.

Em se tratando de planejamento urbano e da forma como a ocupação dos centros urbanos se dá, Christofoletti (2008) destaca a interferência direta da ação antrópica especialmente sobre a infiltração quando aponta que

a ampliação das áreas urbanizadas, devido à construção de áreas impermeabilizadas, repercute na capacidade de infiltração das águas no solo, favorecendo o escoamento superficial, a concentração das enxurradas e a ocorrência de ondas de cheia. A urbanização afeta o funcionamento do ciclo hidrológico, pois interfere no rearranjo dos armazenamentos e na trajetória das águas. Introduzindo novas maneiras para a transferência das águas, na área urbanizada e em torno das cidades, provoca alterações na estocagem hídrica nas áreas circunvizinhas e ocasiona possíveis efeitos adversos e imprevistos, no tocante ao uso do solo (CHRISTOFOLETTI, 2008, p.424).

Na política municipal brasileira, o Plano Diretor é o instrumento básico para o desenvolvimento e a expansão urbana do município (Brasil, 2001, artigo 40). Sua elaboração é realizada em municípios com mais de 20.000 habitantes e conta com a participação do prefeito, da Câmara Municipal e da população. Sua função é promover maior desenvolvimento para o município e melhor gestão, além de direcionar as prioridades dos investimentos e favorecer um crescimento urbano sustentável. 
No município de Belo Horizonte há legislações específicas que regulamentam o uso do solo, como é o caso do Plano Diretor (Lei no 7.165/1996) e da Lei de Parcelamento, Ocupação e Uso do Solo (LPOUS), Lei no 7.166/1996. No Plano Diretor foi definido o zoneamento do município que, conforme Caldas et al (2008, p.508) consiste na "divisão do território em zonas, em função de suas características ou potencialidades". E na Lei ํㅜ 7.166/1996 foram feitas a definição e a diferenciação entre tais zonas, seguindo os potenciais de adensamento, além das demandas de preservação e proteção ambiental, cultural, histórica, paisagística e arqueológica. Ou seja, é a LPOUS que define as possibilidades de uso e ocupação no território municipal. Portanto, as análises realizadas neste estudo são baseadas nesta lei, com suas modificações até o ano de 2016.

Mello (1982) denomina zoneamento a disciplina condicionadora do uso da propriedade imobiliária mediante delimitação de áreas categorizadas em vista das utilizações urbanas nelas admitidas. Já Silva (1995) define zoneamento

como um procedimento urbanístico destinado a fixar os usos adequados para as diversas áreas do solo municipal ou a repartição do território municipal à vista da destinação da terra, do uso do solo ou das características arquitetônicas (SILVA, 1995, p.214).

Em Belo Horizonte, a legislação municipal (LPOUS) define as seguintes zonas: Zona de Preservação Ambiental (ZPAM), Zona de Proteção (ZP), Zona de Adensamento Restrito (ZAR), Zona de Adensamento Preferencial (ZAP), Zona Central (ZC), Zona Adensada (ZA), Zona de Especial Interesse Social (ZEIS), Zona de Grandes Equipamentos (ZE), conforme Figura 1.

Salienta-se que as próprias características físicas do município favorecem a ocorrência de riscos geológicos em função de seus condicionantes geomorfológicos e geológicos, podendo ocorrer processos erosivos e movimentos de massa em algumas áreas específicas. Logo, o zoneamento municipal também deve considerar tais aspectos para restringir o uso do solo nestas regiões. Daí a importância de estudos que relacionem os locais considerados como áreas de risco com o nível de restrição à ocupação, como forma de analisar a efetividade das políticas públicas.

Dessa maneira, o presente trabalho apresenta como objetivo realizar um levantamento das áreas predispostas a risco geológico elevado em Belo Horizonte, relacionando-as com o zoneamento do território, com o intuito de verificar, de maneira qualitativa e quantitativa, possíveis incompatibilidades no planejamento urbano em locais definidos como vulneráveis do ponto de vista geológico.

\section{CARACTERIZAÇÃo DA ÁREA}

O município de Belo Horizonte possui $330,9 \mathrm{~km}^{2}$ de área, de acordo com o Instituto Brasileiro de Geografia e Estatística (IBGE), e está situado no estado de Minas Gerais, na região Sudeste do Brasil. Em termos administrativos, a Prefeitura Municipal de Belo Horizonte (PBH) trata o planejamento e a gestão do território a partir da divisão deste em nove áreas, denominadas regionais (Figura 2).

A estrutura geológica do estado é formada por crátons, estruturas estáveis e que apresentam composição antiga, gerando maior resistência ao território. $O$ relevo é predominantemente formado por planaltos, com presença de depressões no setor norte. A existência de planaltos pode dificultar a ocupação, sendo necessário em alguns casos o emprego de técnicas conservacionistas nessas áreas.

O território mineiro apresenta clima tropical típico e tropical de altitude, sendo o primeiro caracterizado por verões chuvosos e períodos de estiagem no inverno e o segundo por características similares, porém com invernos mais rigorosos. Em Belo Horizonte, 
especificamente, há predomínio do clima tropical de altitude. Em termos de distribuição vegetal, em Minas Gerais encontram-se dois domínios, sendo eles a Mata Atlântica e o Cerrado, além de uma área de transição na qual o município de Belo Horizonte está inserido. Salienta-se que o norte do estado é caracterizado, ainda, pela presença de espécies típicas da Caatinga.

Figura 1 - Zoneamento do município de Belo Horizonte.

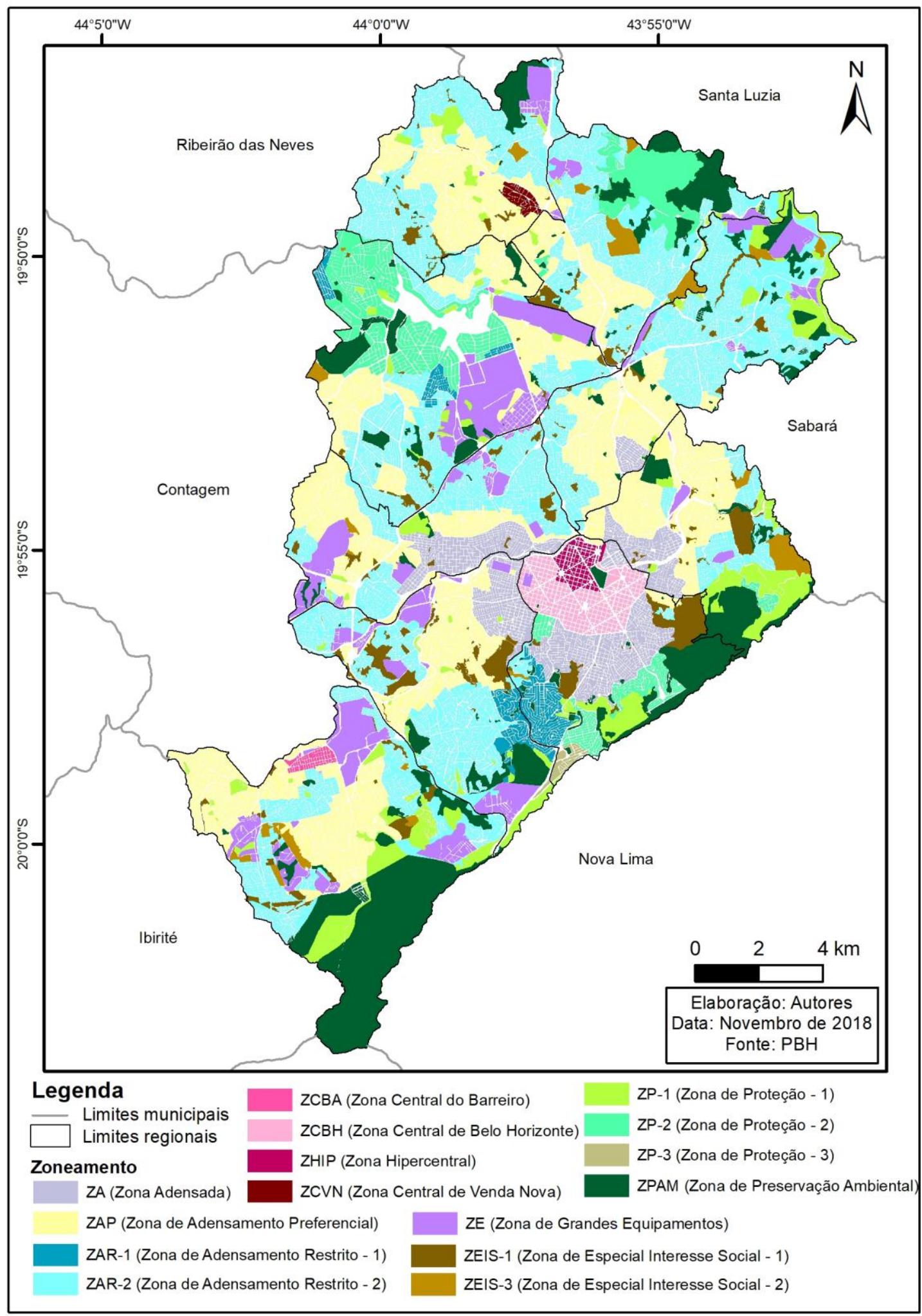


Figura 2 - Regionais administrativas de Belo Horizonte.

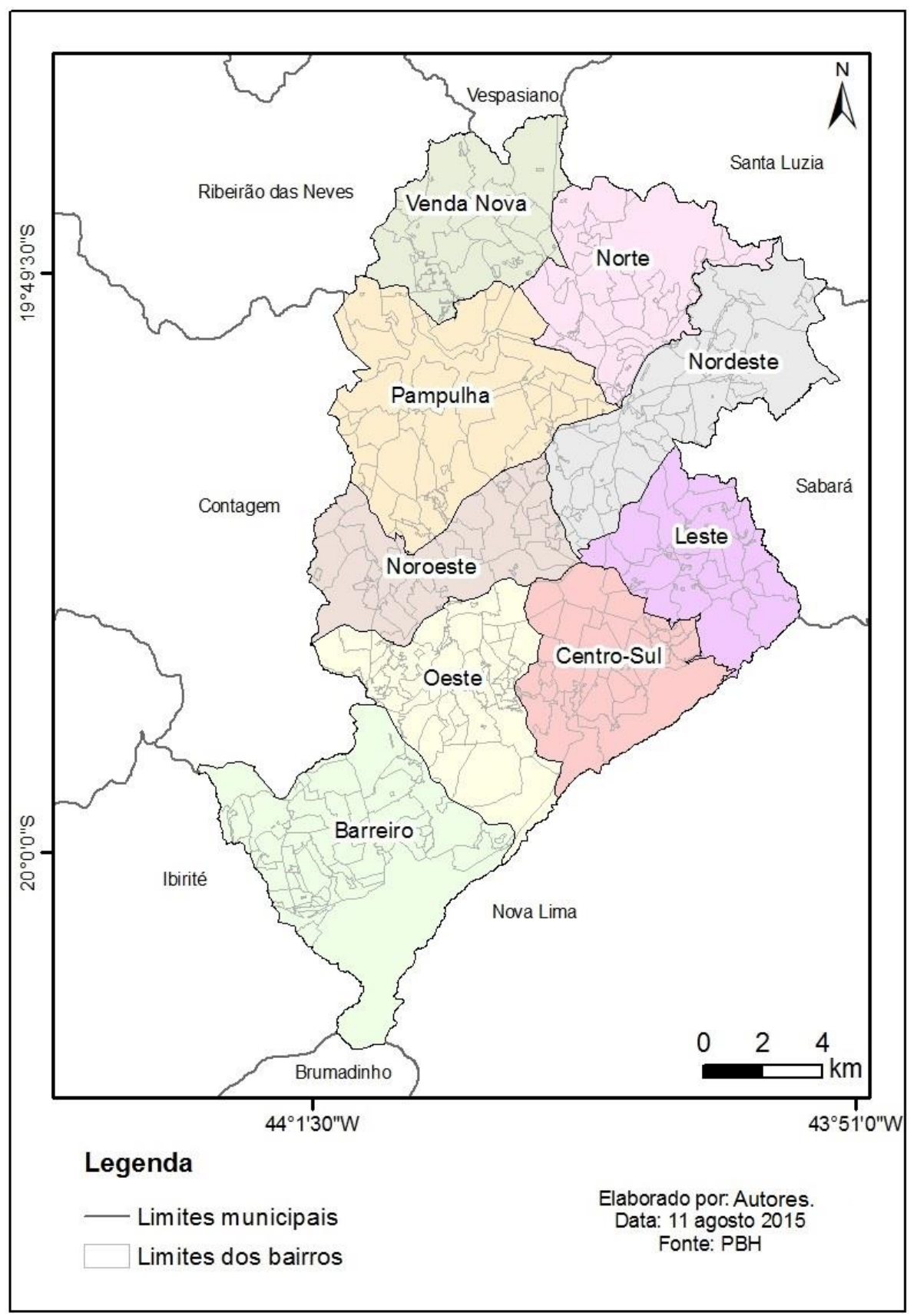

Os aspectos físicos que mais se destacam nas análises associadas à risco geológico são os condicionantes geomorfológicos e geológicos, representados pelas características litológicas. Em termos de distribuição altimétrica, é possível afirmar que Belo Horizonte possui altitudes entre $675 \mathrm{~m}$ e $1505 \mathrm{~m}$, uma vez que está inserida em área com predominância de relevo planáltico, conforme citado anteriormente. Ao sul do município, na divisa entre Belo Horizonte, Nova Lima, Brumadinho e lbirité, se localiza a maior altimetria, sendo essa entre $1320 \mathrm{~m}$ e $1505 \mathrm{~m}$. Já nas partes correspondentes as regionais Norte e Nordeste se localizam as menores altimetrias, entre $655 \mathrm{~m}$ e $720 \mathrm{~m}$. Observa-se que as áreas mais declivosas se encontram nos 
limites do município, tanto a leste e sudeste, onde se dá o alinhamento da Serra do Curral, quanto no limite norte. Figuras 3 e 4.

Figura 3 - Mapa altimétrico de Belo Horizonte.

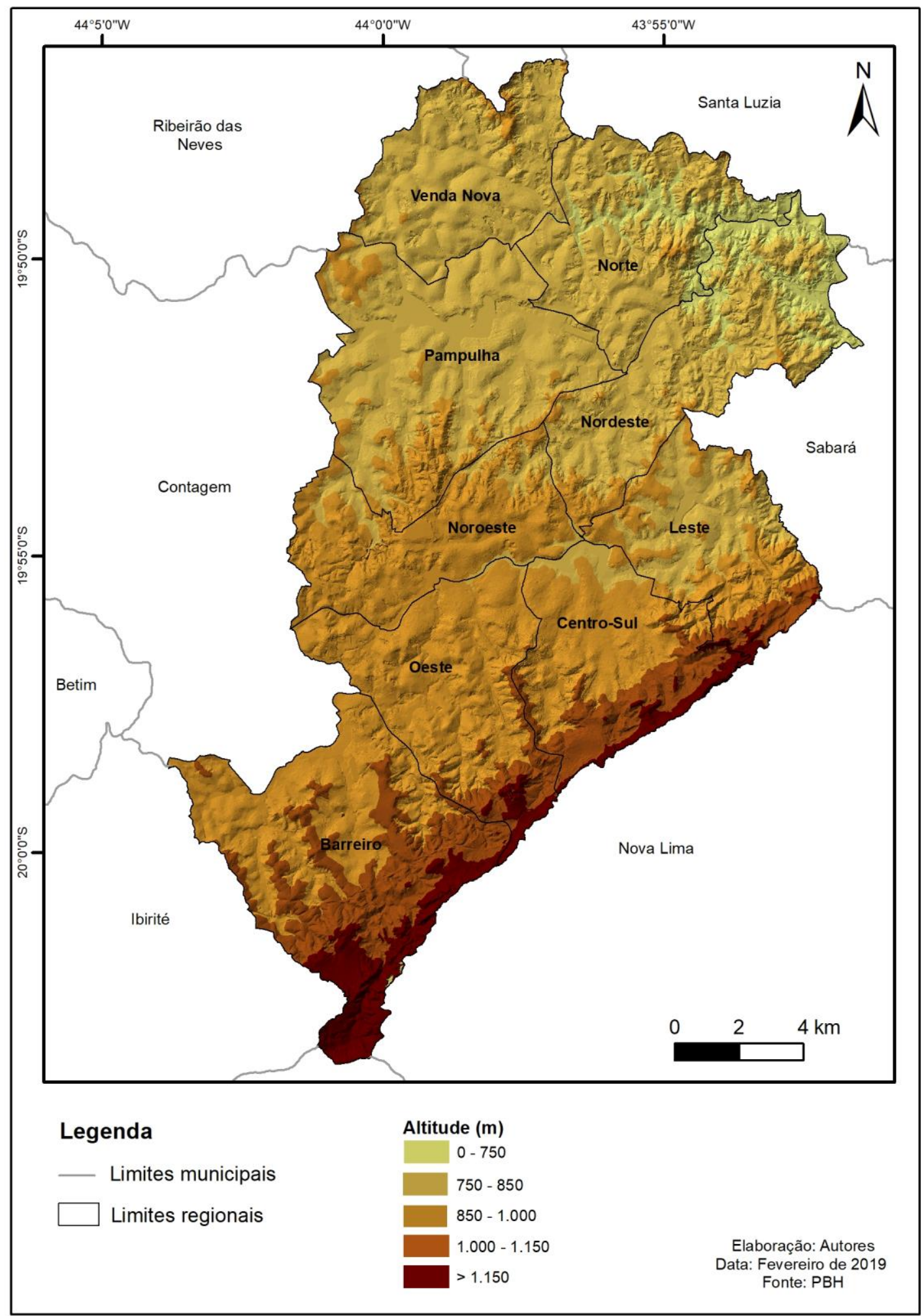


Figura 4 - Mapa de declividade de Belo Horizonte.

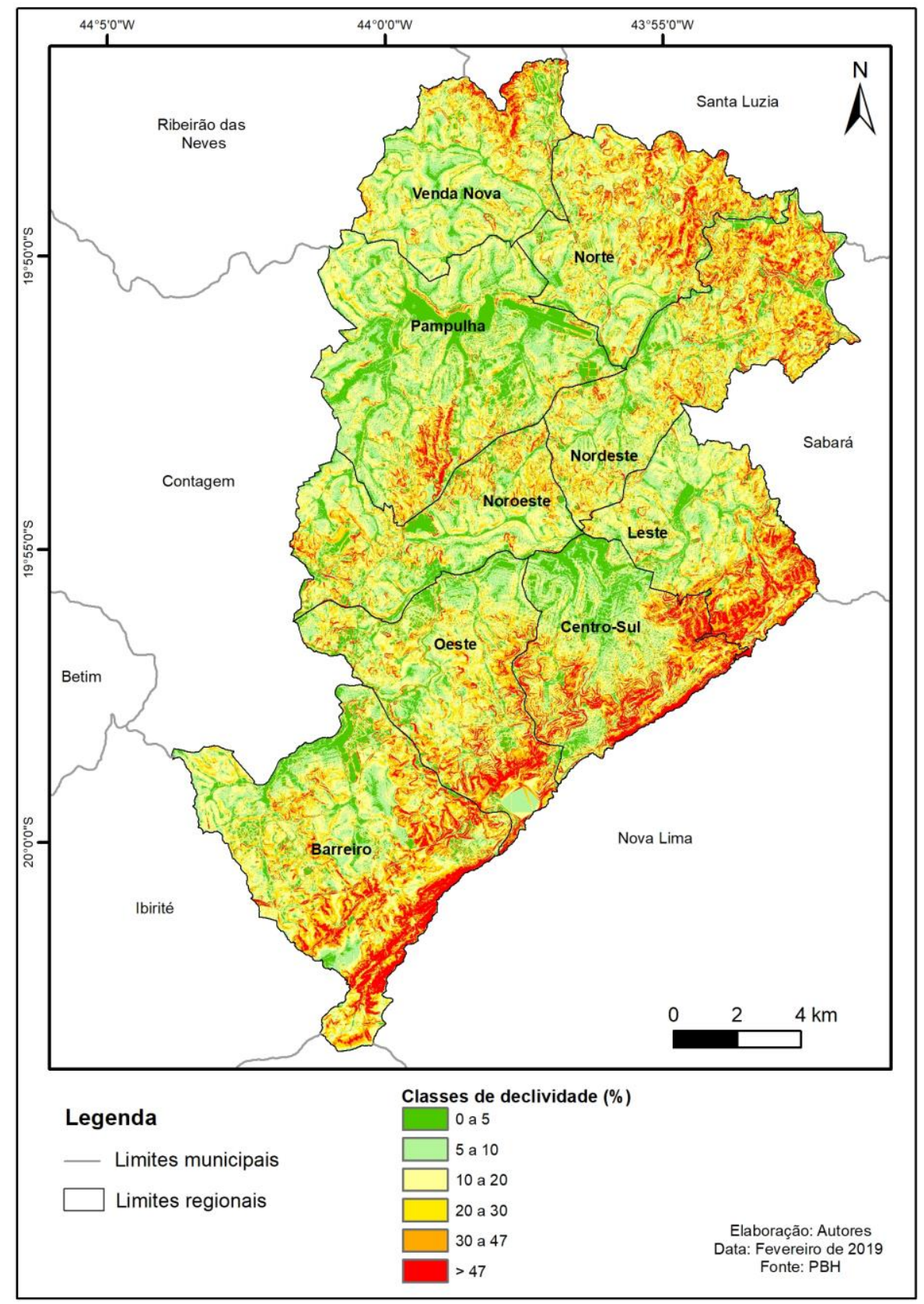

Documentos e mapeamentos disponibilizados pela $\mathrm{PBH}$ em relação à distribuição litológica no município apontam a ocorrência de gnaisses no Domínio do Complexo Belo Horizonte, itabiritos, dolomitos e filitos no Domínio das Rochas Metassedimentares, além de rochas das Formações Gandarela (itabiritos e filitosdolomíticos) e Cercadinho (quartzitos e filitos). Quanto aos condicionantes morfológicos e hidrográficos, verifica-se que em Belo Horizonte há predominância de vertentes planas ou convexas de média declividade $(10 \%$ a $30 \%)$ e de vertentes planas ou convexas de alta declividade $(>30 \%)$, além de côncavas de média declividade $(10 \%$ a $30 \%)$. A presença dessas vertentes está associada à formação de tipos distintos de solos na região, sendo as planas e convexas responsáveis pela formação de Latossolos, solos desenvolvidos que possuem os horizontes A, B e C, além de baixa fertilidade, necessitando, portanto, da aplicação de técnicas agrícolas para que possam ser utilizados. Nas vertentes côncavas há presença de Argissolos, que possuem o horizonte B preenchido por argila sendo denominado de B textural (SANTOS et al, 2018). Destaca-se que esse 
preenchimento pode levar a saturação de água no horizonte $A$ ocasionando movimentos de massa que acontecem anualmente em Belo Horizonte e que acarretam em diversos prejuízos em âmbitos sociais, econômicos e ambientais (FERNANDES, 2013).

\section{METODOLOGIA}

Para que os objetivos do estudo fossem alcançados, algumas etapas foram cumpridas, sendo que primeiramente foi feito levantamento bibliográfico acerca dos conteúdos abordados na pesquisa, como os conceitos de áreas de risco, uso do solo e zoneamento. Em seguida, ainda como forma de embasar a temática que está sendo discutida, foi feita uma análise da Lei Municipal de Parcelamento, Ocupação e Uso do Solo (Lei no 7.166/1996), e suas alterações, para esclarecimentos e definições em relação ao zoneamento de Belo Horizonte.

A partir do levantamento das informações supracitadas, foi feita consulta à Prefeitura Municipal de Belo Horizonte, em especial à Secretaria Municipal Adjunta de Planejamento Urbano (SMAPU), para a qual foram solicitadas bases cartográficas relativas ao zoneamento e as áreas de predisposição a riscos geológicos no município.

A base cartográfica relativa ao zoneamento municipal constitui documento oficial que representa as zonas, por quadra, conforme definição da Lei de Parcelamento, Ocupação e Uso do Solo (Lei 7.166/96, incluindo as alterações até a Lei 9.959/10), tal arquivo é atualizado periodicamente por funcionários da SMAPU. Já a base cartográfica relativa à predisposição a riscos geológicos em Belo Horizonte, apresenta informações baseadas na gradação da intensidade de tal predisposição, de acordo com a susceptibilidade do terreno. Este arquivo considera os seguintes tipos de risco geológico: escorregamento; escavação; erosão; assoreamento; inundação; poluição/contaminação do lençol freático; e risco associado a cavidades abandonadas. Salienta-se, ainda, que esta base fornecida pela SMAPU foi elaborada a partir da proposta apresentada por Silva et al. (1995) em um relatório sobre os aspectos geológicos, hidrogeológicos, geotécnicos e geoambientais de Belo Horizonte.

A análise dos dados enviados pela SMAPU mostrou-se de grande valor para 0 desenvolvimento da pesquisa, uma vez que apresentam as áreas predispostas ao risco geológico e explica a razão de serem consideradas dessa maneira. Além disso, esses arquivos explicitam quais e como os riscos geológicos são considerados, pelo produto entre a probabilidade de ocorrência e dano que será causado, e a magnitude dos mesmos para a cidade de Belo Horizonte. Constatou-se a classificação dos riscos geológicos em: baixo, médio, alto e elevado. Definiu-se como objeto deste estudo as áreas predispostas a risco geológico na categoria elevado.

Para cumprir o objetivo de realizar a sobreposição entre as informações de áreas predispostas a risco geológico elevado e do zoneamento foram feitos processamentos dos dados fornecidos, sendo estes produzidos em software específico para geoprocessamento, no caso o ArcMap. Dessa forma, a partir da base cartográfica de predisposição à risco geológico, foram selecionadas apenas as áreas em que a predisposição é classificada como elevada, tendo sido gerada uma nova base cartográfica composta. Em seguida, esta base gerada foi sobreposta a base cartográfica do zoneamento municipal por quadras. A partir dessa sobreposição, uma outra base foi gerada, sendo ela composta pela interseção entre predisposição elevada e zoneamento e apresentada na Figura 5. Este produto foi, portanto, analisado de maneira qualitativa e quantitativa (identificação das zonas em que a predisposição é elevada, descrição de tais zonas, com apontamentos para o nível de permissividade de ocupação em cada zona, estatística de quais zonas são mais presentes), permitindo a elaboração de tabelas e gráficos para apresentação dos resultados obtidos.

\section{RESULTADOS E DISCUSSÃO}

Dos sete riscos geológicos elencados pelo documento oficial fornecido pela SMAPU e citados anteriormente, foram considerados, neste trabalho, erosão, assoreamento, inundação, poluição do lençol freático, escorregamentos, sendo que em primeira análise foi observado que estes diferentes tipos de riscos coincidem em termos de área de ocorrência no município. Além disso, 
as áreas predispostas a risco geológico elevado em Belo Horizonte equivalem a $85,11 \mathrm{~km}^{2}$, correspondendo a $25,7 \%$ do território (Figura 5). Ou seja, percebe-se que pouco mais de 1/4 do município apresenta características físicas que propiciam a ocorrência de eventos geológicos de intensidade elevada capazes de causar danos à população.

Figura 5 - Áreas predispostas a risco geológico elevado de acordo com o zoneamento municipal.

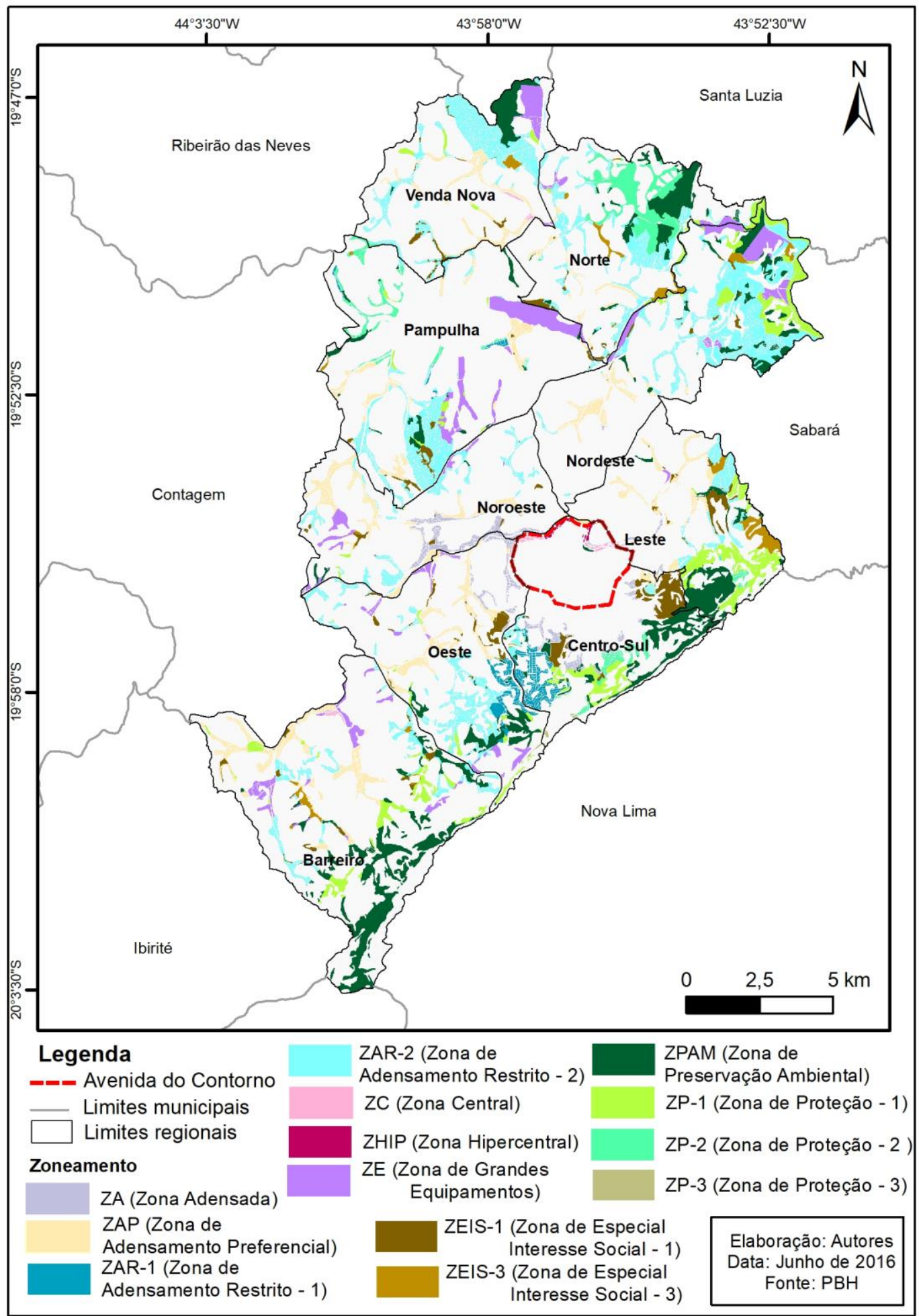


Em termos de análise por regional, a Tabela 2 quantifica os dados relativos à área da regional e áreas predispostas a risco geológico elevado em cada uma das nove regionais.

Tabela 2 - Relação entre área da regional e área predisposta a risco geológico elevado.

\begin{tabular}{ccc} 
Regional & Área $\left.\mathbf{( k m}^{2}\right)$ & Áreas predispostas $\left.\mathbf{( k m}^{2}\right)$ \\
\hline Barreiro & 53,46 & 12,69 \\
\hline Centro-Sul & 31,73 & 8,30 \\
\hline Leste & 27,9 & 8,42 \\
\hline Nordeste & 39,33 & 13,73 \\
\hline Noroeste & 30,08 & 4,98 \\
\hline Norte & 32,56 & 10,42 \\
\hline Oeste & 35,93 & 8,50 \\
\hline Pampulha & 51,04 & 9,92 \\
\hline Venda Nova & 29,16 & 8,15
\end{tabular}

Fonte - Elaborado pelos autores.

Observa-se que, ainda que a regional Barreiro seja a maior do município $\left(53,46 \mathrm{~km}^{2}\right)$, o tamanho das áreas predispostas nesta regional e na Nordeste são aproximadas, sendo 12,69 $\mathrm{km}^{2}$ na Barreiro e $13,73 \mathrm{~km}^{2}$ na Nordeste. Assim, torna-se necessário realizar uma análise relativizando a relação, o que é possível trabalhando com as porcentagens das áreas predispostas em cada regional, conforme apresentado no Figura 6.

Figura 6 - Porcentagem de áreas predispostas a risco geológico elevado por regional.

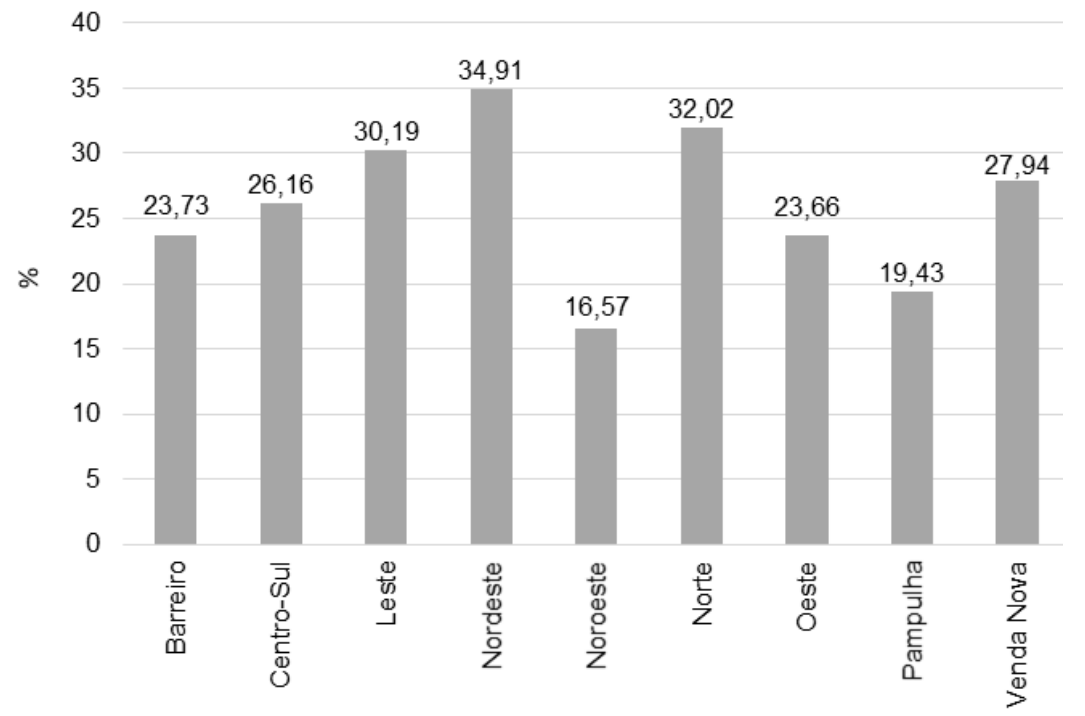

Fonte - elaborado pelos autores com base em dados disponibilizados pela $\mathrm{PBH}$.

As regionais que se destacam com a presença de área predisposta a risco geológico elevado são Nordeste, Norte e Leste, com 34,91\%, 32,02\% e 30,19\%, respectivamente. Nota-se que todas as regionais possuem mais de $15 \%$ de sua área em locais cujas características litológicas, morfológicas e hidrológicas condicionam a ocorrência de eventos geológicos capazes de causar perdas significativas. As regionais com menos áreas predispostas são Pampulha (19,43\%) e Noroeste (16,57\%).

O estudo dos riscos geológicos torna-se importante na medida em que eles podem gerar diversos problemas que afetam diretamente os âmbitos sociais, políticos e econômicos de Belo Horizonte. Sendo assim, o Zoneamento deveria restringir a ocupação em áreas predispostas ao risco geológico elevado com o objetivo de minimizar esses efeitos e possíveis danos que venham a ser causados à população. Considerando que a Lei de Parcelamento, Ocupação e 
Uso do Solo define as características de cada zona, bem como a restrição à ocupação em cada uma delas, é possível afirmar que as Zonas de Preservação Ambiental (ZPAM), Zonas de Proteção Ambiental 1, 2 e 3 (ZP's 1,2 e 3), e as Zonas de Grandes Equipamentos (ZE's), podem ser consideradas como não permissivas à moradia, já que possuem restrições à ocupação; as Zonas de Adensamento Restrito 1 e 2 (ZAR 1 e 2) são permissíveis, no entanto com algumas restrições; e as Zonas de Adensamento Preferencial (ZAP), Zonas de Adensamento (ZA), Zonas Hiper Centrais (ZH), Zonas Centrais (ZC) e as Zonas de Especial Interesse Social 1 e 3 (ZEIS 1 e 3) são consideradas permissíveis (Figura 7).

Figura 7 - Permissividade do zoneamento nas áreas com predisposição a risco geológico elevado.

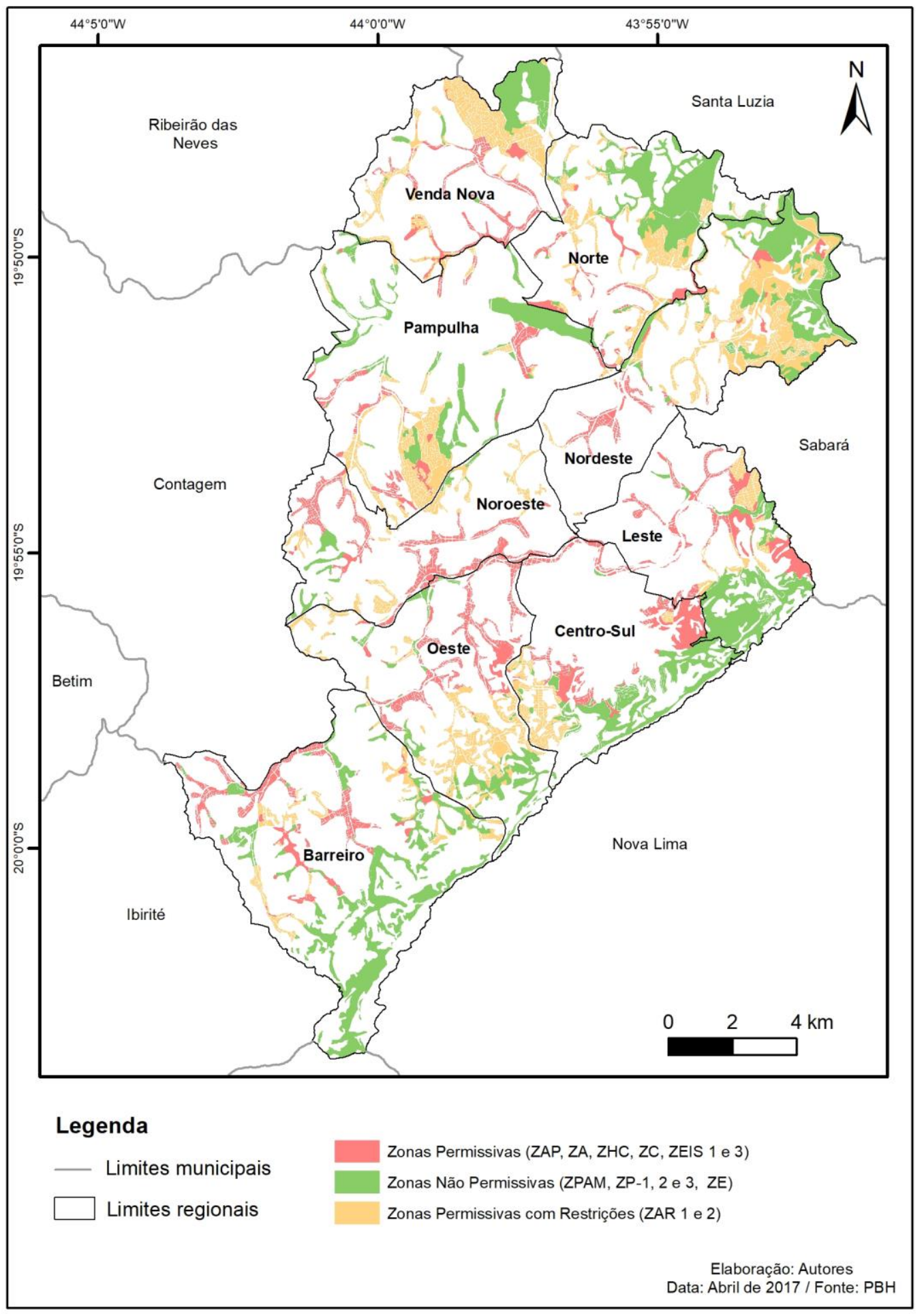


A predisposição ao risco geológico afeta todas as Zonas, de maneira que podem ocorrer consequências negativas à população. As Zonas de Especial Interesse Social 1 e 3 (ZEIS 1 e 3) são tratadas de maneira distinta pela $\mathrm{PBH}$ em comparação as outras, já que nestas há atuação da Companhia Urbanizadora de Belo Horizonte (URBEL) que, em conjunto com o Grupo Executivo de Áreas de Risco (GEAR) e os Núcleos de Defesa Civil (NUDEC), fiscaliza, monitora e realiza medidas mitigadoras aos riscos geológicos que afetam essas áreas, através do Programa Estrutural em Áreas de Risco (PEAR), proporcionando, assim, maior segurança aos habitantes desde a metade da década de 90 (VOLPONI, 2014).

Em termos de análise municipal, pode-se observar a distribuição da predisposição a risco geológico elevado por zona no mapa apresentado na Figura 5. Quando se analisa o mapa da distribuição das áreas com predisposição a risco geológico elevado no território de Belo Horizonte, alguns aspectos se destacam: a regional Centro-Sul apresenta um grande vazio, situado nos limites da avenida do Contorno, o que pode ser explicado pelo projeto de urbanização planejada definido por Aarão Reis durante o surgimento da cidade; a Pampulha também apresenta um vazio, que pode ser justificado pela presença da lagoa projetada por Oscar Niemeyer a pedido do prefeito da época: Juscelino Kubitscheck; a concentração de áreas predispostas a risco geológico elevado nos limites do município, especialmente nas porções norte e sudeste, que explicitam a necessidade de um zoneamento intermunicipal, tornando mais fácil a tomada de decisões e implementação de medidas que diminuam a predisposição ao risco geológico.

Há, no município, um predomínio de áreas com predisoposição ao risco geológico elevado nas Zonas de Adensamento Restrito-2 (ZAR-2), de Preservação Ambiental (ZPAM) e de Adensamento Preferencial (ZAP). As porcentagens de cada zona presente em área predisposta a risco elevado são apresentadas na Figura 8 . Nota-se que $23,45 \%$ das áreas com predisposição ao risco geológico elevado apresenta incroguência em relação ao Zoneamento, sendo esta definida pelo somatório das porcentagens das áreas permissivas à ocupação, quais sejam, Zona de Adensamento Preferencial (ZAP), com 12,04\%, Zona Central (ZC), com 0,38\%, Zona Hiper Central (ZHIP), com 0,15\%, Zona Adensada (ZA), com 2,87\%, e as Zonas de Especial Interesse Social (ZEIS 1 e 3), com 8,01\%. Porém, é importante salientar que as últimas possuem tratamento diferenciado no município, já que a URBEL atua diretamente na mitigação dos riscos nestas áreas. Ou seja, do total de 23,45\%, 8,01\% já apresentam programas de intervenção específicos para a minimização dos danos causados por riscos geológicos. Logo, os $14,44 \%$ restantes constiutem áreas em que a ocupação deveria ser restrita ou, quando permitida, que fosse garantida a existência de políticas públicas voltadas para os problemas relacionados aos riscos. Cabe salientar, contudo, que a ocupação municipal reflete o processo histórico de crescimento urbano de Belo Horizonte, e este ocorreu de maneira tardia e rápida, como em outras cidades brasileiras. Assim, é possível constatar que, muitas vezes, o planejamento urbano também se deu tardiamento, não acompanhando ou subsidiando a ocupação.

O restante das áreas analisadas, ou seja, 76,55\%, não apresenta problemas em relação a permissividade da habitação, pois não são habitados ou, quando são, apresentam restrições. Tais áreas encontram-se distribuídas entre Zonas de Preservação Ambiental (ZPAM), com 20,34\%, Zonas de Proteção 1, 2 e 3 (ZP-1, ZP-2 e ZP-3), com 10,04\%, 5,79\% e 0,07\%, respectivamente, Zona de Adensamento Restrito 1 e 2 (ZAR-1 e ZAR-2), com 2,52\% e 28,05\%, respectivamente, e Zonas de Grandes Equipamentos (ZE), com 9,76\%. 
Figura 8 - Zonas em áreas de predisposição a risco geológico elevado, em porcentagem, em Belo Horizonte.

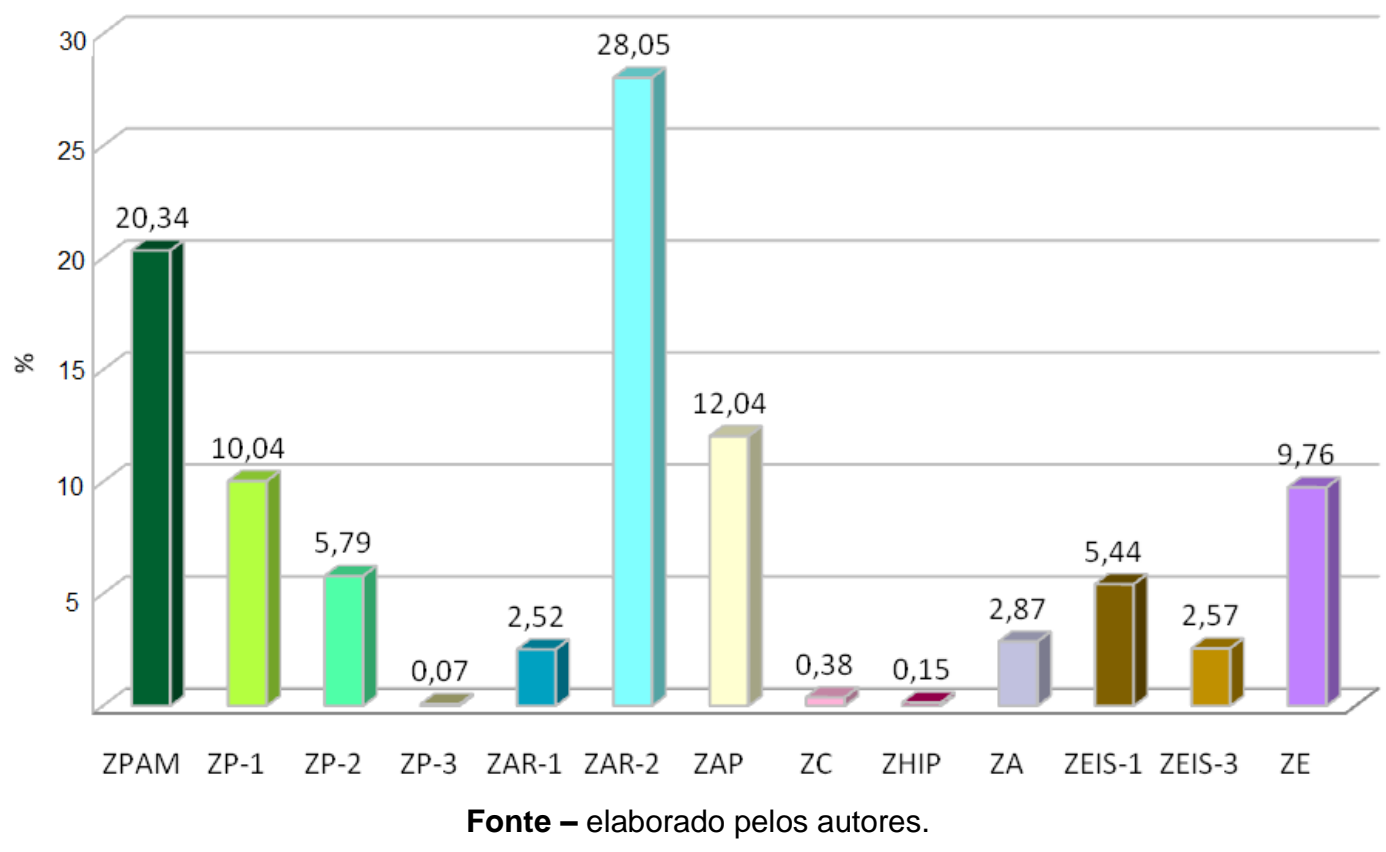

Observa-se, assim, que Belo Horizonte, como a maior parte das cidades brasileiras, possui uma legislação municipal ainda permissiva em relação à ocupação em áreas predispostas a riscos geológicos. Isso evidencia a necessidade de um planejamento urbano que limite o adensamento nessas áreas e defina parâmetros urbanísticos compatíveis com o risco identificado.

Em Belo Horizonte, a negligência na ficalização ou a permissividade de edificações em áreas predispostas a risco geológico elevado favorecem deslizamentos de terras e perdas humanas e materiais nos períodos de chuva. Desse modo, um zoneamento restritivo de uso e ocupação da terra nessas áreas necessita ser rigorosamente fiscalizado e monitorado pelo poder público, minimizando a ocorrência de desastres naturais no município, como ocorre nas áreas de ZEIS por meio da atuação da URBEL.

\section{CONSIDERAÇÕES FINAIS}

A partir dos dados levantados e das análises realizadas, algumas considerações podem ser apresentadas:

1. As Zonas que mais se destacam, em termos de predisposição ao risco geológico elevado, são: ZAR-2, ZPAM, ZAP, ZP-1 e ZE, sendo somente a ZAP considerada permissiva à ocupação, podendo acarretar diversos problemas associados aos fenômenos geológicos tratados.

2. Considera-se importante que programas como o PEAR sejam ampliados e praticados em todo o município, especialmente nas áreas em que há risco geológico elevado em zonas permissivas à ocupação, como a ZAP.

3. As áreas consideradas neste trabalho como zonas permissivas devem se tornar prioritarias quando forem discutidas alterações nas legislações que influenciam no uso e ocupação do solo no município.

4. Nas áreas limítrofes do município de Belo Horizonte há necessidade de planejamento em nível intermunicipal, tendo em vista que existem áreas predispostas a risco geológico elevado nestes locais. O planejamento adequado nesse sentido facilitaria a tomada de decisões, bem 
como a implementação de medidas, como o PEAR, ou adaptação do mesmo, nos outros municípios, que diminuam a predisposição ao risco geológico.

\section{AGRADECIMENTOS}

Os autores agradecem à Secretaria Municipal Adjunta de Planejamento Urbano da Prefeitura de Belo Horizonte, pelo fornecimento dos dados. Agradecem, também, as instituições de ensino, ao Centro Federal de Educação Tecnológica de Minas Gerais (CEFET-MG), sendo que este, juntamente à FAPEMIG, financiou a pesquisa no ano de 2016, e ao Programa de PósGraduação em Geografia do Instituto de Geociências da Universidade Federal de Minas Gerais (UFMG).

\section{REFERÊNCIAS}

BELO HORIZONTE. Lei no 7.165/1996, de 27 de agosto de 1996. Institui o Plano Diretor do Município de Belo Horizonte. Belo Horizonte (1996). Disponível em https://prefeitura.pbh.gov.br/sites/default/files/estrutura-de-governo/politicaurbana/Lei 7165 Plano Diretor.pdf > acesso em Março de 2018.

BELO HORIZONTE. Lei no 7.166/1996, de 27 de agosto de 1996. Estabelece normas e condições para parcelamento, ocupação e uso do solo urbano no município. Belo Horizonte (1996). Disponível em https://leismunicipais.com.br/a/mg/b/belo-horizonte/leiordinaria/1996/716/7166/lei-ordinaria-n-7166-1996-estabelece-normas-e-condicoes-paraparcelamento-ocupacao-e-uso-do-solo-urbano-no-municipio > acesso em março de 2018.

BIGARELLA, J. J. Estrutura e Origem das Paisagens Tropicais e Subtropicais. Volume 3. Editora UFSC, Florianópolis, 2003.

BRASIL. Lei no 10.257, de 10 de julho de 2001. Regulamenta os arts. 182 e 183 da Constituição Federal, estabelece diretrizes gerais da política urbana e dá outras providências. Brasília (2001). Disponível em http://www.planalto.gov.br/ccivil 03/LEIS/LEIS 2001/L10257.htm > acesso em Março de 2018.

CALDAS, M. F., MENDONÇA, J, G., CARMO, L. N., (coord.) Estudos urbanos: Belo Horizonte 2008: transformações recentes na estrutura urbana. Belo Horizonte: Prefeitura de Belo Horizonte, 2008. 513p.

CHRISTOFOLETTI, A. Aplicabilidade do conhecimento geomorfológico nos projetos de planejamento. In: GUERRA, A. J. T.; CUNHA, S. B. (org). Geomorfologia: Uma Atualização de Bases e Conceitos. 8 ed. Rio de Janeiro: Bertrand Brasil, 2008, cap 11, p. 415-440.

FERNANDES, M. R., LEAL, J. T. C., MELLO, M. S., MOREIRA, M. A. B., ALBANEZ, A. C. M. P. Minas Gerais: caracterização de unidades de paisagem. Belo Horizonte: EMATER - MG, 2013.

GAMA, J. R. N. F. Solos: manejo e interpretação. Belém: Embrapa Amazônia Oriental, 2004

GUERRA, A. J. T. O início do processo erosivo. In: GUERRA, A. J. T.; CUNHA, S. B. (org). Erosão e conservação dos solos: conceitos, temas e aplicações. Rio de Janeiro: Bertrand Brasil, 1995, 340p.

IBGE - INSTITUTO BRASILEIRO DE GEOGRAFIA E ESTATÍSTICA. Disponível em: http://www.ibge.gov.br/home/. Acesso em: 27 de março de 2016.

KOBIYAMA, M., MENDONÇA, M., MORENO, D. A., MARCELINO, I. P. V. O. M., MARCELINO, E. V., GONÇALVES, E. F., BRAZETTI, L. L. P., GOERL, R. F., MOLLERI, G. S. F., RUDORFF, F. M. Prevenção de desastres naturais: conceitos básicos. Curitiba: Organic Trading, 1 ed., 2006.

MELLO, C. A. B. Natureza jurídica do zoneamento - efeitos. RDA, 1982, 147:23-34.

NUNES, L. H. Urbanização e desastres naturais. São Paulo: Oficina de Textos, 2015. 
PBH - PREFEITURA DE BELO HORIZONTE -. Disponível em: http://gestaocompartilhada.pbh.gov.br/. Acesso em 10 de fevereiro de 2017.

SANTOS, H. G., JACOMINE, P. K. T., ANJOS, L. H. C. dos, OLIVEIRA, V. A. de, LUMBRERAS, J. F., COELHO, M. R., ALMEIDA, J. A. de, ARAUJO FILHO, J. C. de, OLIVEIRA, J. B. de, CUNHA, T. J. F. (editores técnicos). Sistema brasileiro de classificação de solos. 5. ed., ver. e ampl. Brasília, DF: Embrapa, 2018. 306 p.

SILVA, J. A. Direito urbanístico brasileiro. São Paulo: Malheiros Editores, 1995, 2a ed., p. 214.

SILVA, A. B., CARVALHO, E. T., FANTINELI, L. M., ROMANO, A. W., VIANA, C. S. Estudos Geológicos, Hidrogeológicos, Geotécnicos e Geoambientais Integrados no Município de Belo Horizonte. Belo Horizonte: Convênio PBH/FUNDEP (IGC), 1995, 375p.

VOLPONI, I. E. Q. Gestão de áreas de risco geológico em vilas e favelas do município de belo horizonte através do programa estrutural em áreas de risco - PEAR. São Paulo: Seminário URBFAVELAS, 2014.

Recebido em: 10/08/2018

Aceito para publicação em: 15/02/2019 